\section{Atypical Herpes Zoster}

A 12-year-old girl - who was a diagnosed case of connective tissue disorder and was on oral prednisolone (2 $\mathrm{mg} / \mathrm{Kg} / \mathrm{d}$ ) and hydroxychloroquine for 6 months presented with multiple vesiculobullous eruptions over the right hand for 4 days. Eruptions started with tingling sensation and pain. On examination, she had steroid facies, hypertrichosis and hirsutism. Vesicobullous lesions were present on the dermatomal involvement of C8 and T1 (Fig. 1). Investigations revealed normal blood counts erythrocyte sedimentation rate, C-reactive protein, liver function tests and renal function tests. Tzanck smear revealed multinucleated giant cells. A diagnosis of herpes zoster infection was made and patient was started on intravenous acyclovir $(10 \mathrm{mg} / \mathrm{kg}$ every 8 hrly); skin lesions healed within 7 days (Fig. 2).

The diagnosis of herpes zoster is usually based on unilateral pain in a defined area accompanied by a typical rash in the dermatomal distribution of a segmental nerve. Manifestations of herpes zoster in immunocompromised children can be severe and life threatening. Patients with high risk for disseminated disease should receive intravenous acyclovir at $10 \mathrm{mg} / \mathrm{kg}$ every $8 \mathrm{hrly}$. Patients with uncomplicated herpes zoster and low risk for visceral dissemination should be treated with oral acyclovir, famciclovir or valacyclovir. Bijay K Meher, Deepti D Pradhan and
Subhasmita Pattanayak

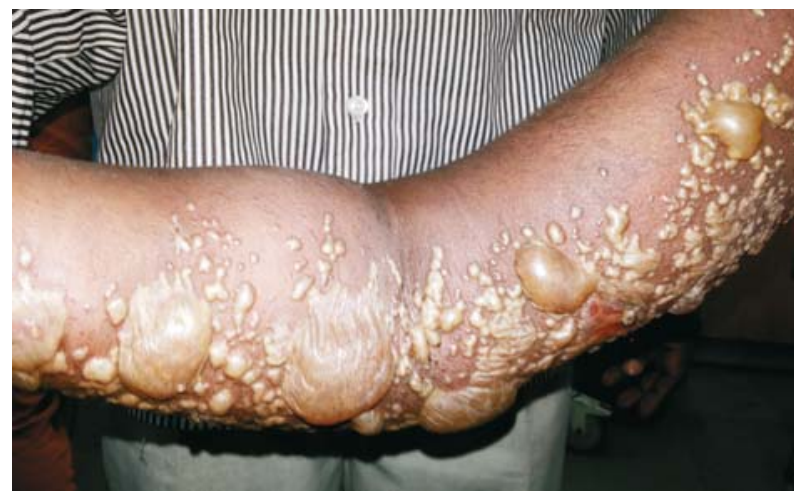

FIG. 1 Vesiculobullous lesions over $C_{8}$ and $T_{1}$ dermatone.

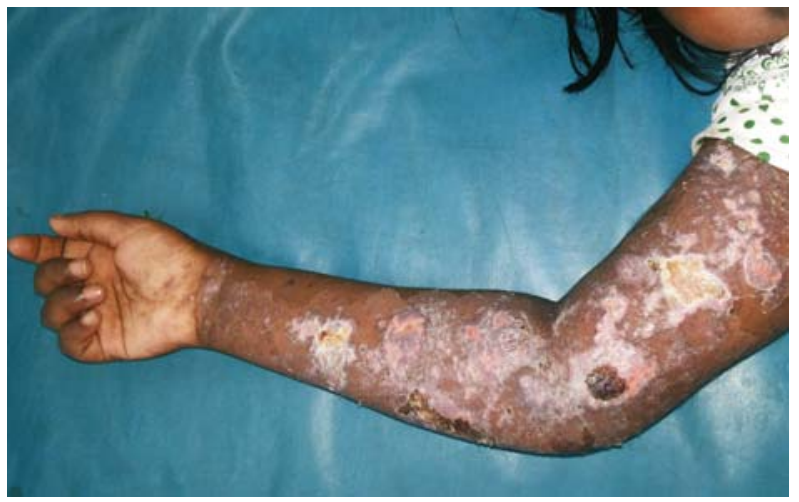

FIG. 2 Lesions showing healing after 1 week of intravenous acyclovir.

Department of Pediatrics, Sardar Vallavbhai Patel Post Graduate Institute of Pediatrics, SCB Medical College, Cuttack, Orissa, India. bkmeher187@yahoo.co.in

\section{Bohn's Nodules}

A full term newborn boy, weighing $3 \mathrm{~kg}$, born out of an uncomplicated pregnancy, was brought to us for evaluation of a few small, white and round bumps on the gingival surface. Examination of the oral cavity showed multiple, firm, pearly-white papules measuring 2 to $4 \mathrm{~mm}$ in diameter, grouped over the vestibular aspect of the alveolar ridge of the maxillary $\operatorname{arch}($ Fig. 1). Two similar lesions were seen on the mandibular area. These lesions were asymptomatic, non-tender, and fixed to the mucosa. Oral mucosa was otherwise normal. A few milia were noted on his chin. Detailed systemic examination was normal. No specific therapy was prescribed. Within a couple of months, most of the lesions subsided spontaneously. Based on the clinical features and the natural course of the disease, a diagnosis of Bohn's nodule was made.

Bohn's nodules are keratin cysts derived from remnants of odontogenic epithelium over the dental 